\title{
Managing asbestos risk
}

\author{
Received (in revised form): 5th October, 2004
}

\section{Daniel Jude}

is an associate in the Construction and Engineering Group of international law firm, DLA Piper Rudnick Gray Cary UK LLP, based in the Liverpool office. He specialises in both contentious and non-contentious construction and engineering matters on behalf of contractors, sub-contractors, employers, funders and professionals. His clients include asbestos removal contractors.

\begin{abstract}
Asbestos is recognised as presenting the biggest occupational health problem ever encountered in the UK. From the 1950 s to the mid-1980s, asbestos was used extensively as a building material throughout the UK. As many as half a million commercial properties still contain asbestos. Research by the Health and Safety Executive (HSE) has revealed that a quarter of the 3,000 people who die each year from asbestos-related diseases once worked in the building or building maintenance trades. These workers are potentially at the highest risk as they could accidentally disturb asbestos while carrying out building works or installing new cables. As a result, Regulation 4 of the Control of Asbestos at Work Regulations 2002 came into force on 21st May, 2004, placing a duty on anyone with responsibility for the repair and maintenance of non-domestic premises to manage any asbestos in the building. The duty to manage will affect landlords, tenants and owner-occupiers of commercial premises. Failure to comply may lead to severe criminal and civil liabilities and the possibility of also being uninsured for the risk. There is also the potential for personal liability upon managers and directors for breach of the regulations. In light of the recent changes, the following paper seeks to provide advice on managing the risk of asbestos in a building.
\end{abstract}

\section{Keywords:}

asbestos, duty holder, non-domestic premises

Daniel Jude

Construction \& Engineering Group DLA Piper Rudnick Gray Cary UK LLP India Buildings

Water Street

Liverpool, L2 oNH, UK

Tel.: +44 (o) 1512374716

Fax: +44 (o)1512369208

E-mail: daniel.jude@dlapiper.com

\section{THE CONTROL OF ASBESTOS AT WORK REGULATIONS 2002}

On 21st May, 2004, Regulation 4 of the Control of Asbestos at Work Regulations 2002 (SI 2002 No. 2675) ${ }^{1}$ — the duty to manage the risk from asbestos in non-domestic premises - came into force, following an 18-month transitional period. The new duty requires those with responsibility for the repair and maintenance of non-domestic premises to find out if there are, or if it is likely that there are, any asbestos-containing materials (ACMs) within the premises. It also requires the responsible persons to record the location and condition of ACMs, to assess and manage any risk from them, and to pass on all information gathered about 
their location and condition to anyone liable to disturb them in future work. These tough new asbestos regulations and a rise in frequency of asbestos-related litigation has made asbestos risk management a top priority for all businesses in the UK.

The government estimates that employers will have to pay £1.5bn to comply with the new regulations. Even more worrying are projections by actuaries that asbestos claims will cost companies and their insurers in excess of US\$200bn in the USA and US\$50bn in Europe. Predictions such as these have provoked a feeling of crisis among many of the world's largest reinsurers, prompting some of them to exclude asbestos liabilities from reinsurance cover altogether. As the situation stands, companies with workplace asbestos exposure are under clear threat.

\section{THE DANGERS OF ASBESTOS}

Asbestos is a generic term that refers to naturally occurring fibrous material silicates of calcium, sodium, iron, magnesium and aluminium. It has been widely used throughout the world because of its binding qualities, high strength and its resistance to heat and corrosive materials. These properties led to the extensive use of asbestos in the construction industry and other industries such as shipbuilding and railway engineering. Many structures built or renovated between 1950 and 1980 still contain asbestos. Although it is now illegal to use any form of asbestos in the construction or refurbishment of any premises, much of what was used in the past is still in place. It is estimated that around 500,000 commercial and public premises are thought to contain some type of asbestos.

Unfortunately, for a long time, the dangers of asbestos were not widely understood. Subsequently, asbestos has been proven to be one of

Biggest occupational health risk the most pernicious occupational health hazards in the world. The Health and Safety Commission describe it as the biggest occupational health risk ever faced by workers in Britain. If disturbed or damaged, asbestos releases fibres into the air which, if inhaled, can accumulate in the lungs and remain there latent for a long time before potentially causing diseases such as:

- Mesothelioma: A cancer of the pleural and peritoneal lining. The disease is considered to be exclusively caused by asbestos exposure and is almost always fatal. It has a long latency period of between 15 and 60 years. There were 1,848 deaths from mesothelioma in 2001 . The annual number of mesothelioma deaths is predicted to continue to rise until it reaches an estimated peak of between 1,950 to 2,450 some time between 2011 and 2015. Over 25 per cent of those dying from mesothelioma have worked in the building or maintenance industries.

- Asbestosis: Scarring of the lung tissue. This is a slow, progressive disease with a latency period typically of 15 to 30 years. There were estimated to be at least 160 deaths from asbestosis in 2001.

- Lung cancer: A malignant tumour of the bronchi covering. Typically this has a latency period of at least 20 years and it is estimated that each 


\section{Dangers to workers}

\author{
Relevant UK legislation
}

year, for every mesothelioma case, there are also between one and two cases of lung cancer attributable to asbestos.

- Diffuse pleural thickening: A non-malignant disease which causes the lining of the lungs to become scarred. It is a chronic condition with no cure and typically has a latency period of at least ten years. According to the Health and Safety Executive (HSE) there were 380 new cases of disablement benefit resulting from diffuse pleural thickening in 2002.

Because of the long latency periods of asbestos-related diseases, many cases of the disease occurring now are as a result of exposure in industries that used asbestos extensively in the past, such as shipbuilding and railway engineering. While virtually all other activities involving potential exposure to asbestos have now ceased, the fact that asbestos was installed in many buildings means that a range of people in the building and maintenance trades still have the potential to be exposed. In this regard, it is important to recognise that, while asbestos is a hazardous material, it can only pose a risk to health if the asbestos fibres become airborne and are then inhaled. Therefore, most asbestos materials pose little risk unless they are disturbed in some way that allows the fibres to be released into the atmosphere and inhaled into the lungs.

It follows from this that workers involved in the refurbishment, repair and maintenance of buildings such as plumbers, carpenters and electricians are included among those potentially at the highest risk. Activities such as drilling, sawing or cutting into the fabric of premises could potentially disturb asbestos and release deadly fibres. The major problem has been that, often, those undertaking these tasks have not known when and where they may encounter asbestos. In many cases, as a result of incomplete and/or non-existent records of building materials, it has been impossible to make an adequate assessment of the risk of asbestos in premises. Frequently, asbestos would be discovered 'accidentally' and building workers would be unwittingly put at risk by dislodging fibres.

It is this risk potential from ACMs that the Control of Asbestos at Work Regulations 2002, in particular Regulation 4, seek to manage. Workers are to be provided with information about the location and condition of ACMs if there is a chance they will be disturbed. The aim is to ensure that, for example, an electrician drilling into a wall in a non-domestic property no longer should be in a situation where he does not know whether he and others will be exposed to potentially deadly asbestos fibres.

\section{THE REGULATORY REGIME - AN OVERVIEW}

The key regulations relating to asbestos are:

- Control of Asbestos at Work Regulations $2002(\text { CAWR })^{2}$ : These regulations consolidate with modifications existing legislation controlling work with asbestos and set out strict requirements for the management of asbestos in non-domestic premises. The bulk of the 
regulations under CAWR came into force on 21st November, 2002 and replaced the Control of Asbestos at Work Act Regulations 1987. ${ }^{3}$

Regulation 4 of CAWR came into force on 21st May, 2004 and imposes a new 'duty to manage' asbestos to enhance the protection of building and maintenance workers from the diseases caused by asbestos exposure.

- Asbestos (Prohibition) Regulations 1992 (as amended 1998) ${ }^{4}$ : These prohibit the import, supply and use of all types of asbestos in the construction or refurbishment of premises. The sale and use of secondhand products containing chrysotile is also prohibited under these regulations.

- Asbestos Licensing Regulations 1983 (as amended 1998)5 : These require specific forms of work with asbestos (including repairing, sealing off or removing asbestos) to be carried out by licensed contractors.

\section{Other relevant regulations}

The duties imposed by CAWR supplement and sit alongside those imposed by existing health and safety regulations including the Health and Safety at Work Act 1974 (HSWA). ${ }^{6}$ The key duties include the general health and safety duties of employers to their employees (s. 2 HSWA) and to others (s. 3 HSWA). Further duties are imposed by s. 4 HSWA on anyone who has control, to any extent, over work premises to ensure the health and safety of others. In addition, the Management of Health and Safety at Work Regulations $1999^{7}$ require employers to carry out risk assessments to manage the health and safety risks posed by hazardous activities. The Control of Substances Hazardous to Health Regulations $1999,{ }^{8}$ the Construction (Design and Management) Regulations $1994^{9}$ and provisions in the Defective Premises Act $1972^{10}$ are also relevant.

\section{Who has a duty to manage?}

\section{CAWR REGULATION 4}

Regulation 4, which imposes the major new obligation, came into force on 21st May, 2004. When CAWR were issued in November 2002,

Regulation 4 was not brought into force immediately; because of the onerous and costly obligations it places on duty holders, an 18-month transitional period was allowed to give companies enough time to budget for and put in place procedures for compliance. Now that Regulation 4 is in force, however, the HSE intends to enforce it rigorously.

\section{Who is affected?}

Regulation 4 places the duty to manage asbestos risk in non-domestic premises and the common areas of domestic premises (which include halls, stairwells, lift shafts and roof spaces) on:

- every person who has, by virtue of any contract or tenancy, an obligation in relation to the maintenance or repair of such premises or means of access to or from the premises; or 


\section{Cooperation}

\section{Duty holders' responsibilities}

- where there is no such contract or tenancy in relation to any part of such premises, every person who has, to any extent, control of that part or means of access to or from it.

The extent of the legal duty therefore is determined by the terms of the agreement or contract that applies and, in the absence of such an agreement, on the degree of control that the party has over the premises. This means that liability will be an issue for many, including (but not limited to) all non-domestic property owners, landlords, managing agents, tenants and licensees - and virtually all employers. Where there is more than one duty holder, the relative contribution of each towards complying with Regulation 4 will be determined by the extent of his or her obligation to maintain and repair the premises. For example, where an employer has control of maintenance activities (either by virtue of a contract, tenancy or as an owner of the premises), it will be the employer's responsibility to comply with the requirements. Where the responsibility for maintenance rests with a different building owner or a managing agent, then the responsibility for compliance will fall with them. In some situations, responsibility may be shared between two or more parties.

It is evident that implementation of the regulations can present different problems in identifying who is responsible for carrying out the necessary surveys and drawing up asbestos management plans, depending on the type of organisation and the premises. Lenders, investors, developers and companies acquiring other businesses also will have to be vigilant in their dealings to avoid inheriting asbestos liabilities, be they civil claims or remediation costs.

Regulation 4 also requires all persons to cooperate with the duty holders to enable them to comply with their duties. For example, a tenant will need to allow a landlord access to a building to carry out a survey. Also, a building surveyor or architect who holds plans which show information on the whereabouts of asbestos would be expected to make these available to the duty holder at a reasonable cost.

\section{What is required of duty holders?}

Regulation 4 creates an explicit duty on those individuals with repair and maintenance responsibilities to assess and manage the risks from asbestosaffected premises. Risk assessments should be carried out to produce a management system or plan, and these plans should detail the actions to be taken and records to be kept to reduce the risk to workers from asbestos.

Duty holders' key responsibilities can be summarised as follows:

— to take reasonable steps to determine the location of materials likely to contain asbestos;

- to make and maintain written records of the location of ACMs;

- to monitor the condition of ACMs; and

- to assess the risk of exposure to ACMs, and document and carry out the actions necessary to manage the risk. 


\section{Sampling and surveying}

Central to the duty to manage asbestos in non-domestic premises is the requirement to complete a suitable assessment. In all cases, this will initially take the form of a survey. In some cases, where no maintenance work is planned or the premises are small, it may be appropriate for the duty holder simply to carry out his own survey; however, if maintenance or refurbishment are planned or the duty holder is responsible for medium-sized or large premises, it is advisable to employ a suitably accredited organisation. The United Kingdom Accreditation Service (UKAS) has developed an accreditation scheme for organisations that carry out asbestos surveys.

The three main objectives of a survey are:

— to locate ACMs (and suspected ACMs), analyse the extent and type and record this information;

— to assess and record the accessibility, condition and surface treatment of known and presumed ACMs; and

- to determine and record the asbestos type, by taking representative samples for laboratory identification or by making a presumption based upon the advice of a competent asbestos surveyor.

\section{HSE guidance}

Risk assessment

The HSE publishes guidance covering the standards and techniques required when surveying workplaces for ACMs and recording the findings. The guidance, entitled Surveying, Sampling and Assessment of Asbestos-containing Materials, ${ }^{11}$ sets the standard for those individuals who commission and complete risk assessments to meet the requirements under the new regulations (HSE, 2003). The guidance covers three types of survey:

- Type 1: Location and assessment survey (or presumptive survey) which is based on assumptions regarding the building infrastructure and materials used in it, deferring the need to sample and analyse until a later date;

- Type 2: Standard sampling, identification and assessment survey (or sampling survey), follows the procedures used in a Type 1 survey, but a representative sample is collected and analysed to determine the presence of asbestos; and

- Type 3: Full access sampling and identification survey (or predemolition or major refurbishment survey), which is based on a full sampling and analytical programme and may involve destructive inspection.

The type of survey required depends on individual circumstances and it may be that a combination of survey types will be required, especially in larger premises.

In order to carry out a meaningful risk assessment, when carrying out a survey and assessing the risk of any ACMs present, both a material assessment and a priority assessment should be included. The material 
assessment should look at the type and condition of any ACMs present and address the likelihood of the ACM releasing airborne fibres if disturbed. The priority assessment should examine the likelihood of someone disturbing the ACM.

\section{Material assessment}

Some ACMs are more vulnerable to damage and more likely to give off fibres than others. To demonstrate, asbestos insulation and lagging can contain up to 85 per cent asbestos and are more likely to give off fibres, while asbestos cement contains only $10-15$ per cent asbestos. The type of ACM and its condition will determine its potential to release asbestos fibres into the air, if disturbed. The condition of ACMs can be considered by the use of an algorithm to carry out the material assessment. This method is recommended in the HSE guidance referred to above (HSE, 2003).

The algorithm is a numerical way of taking into account several influencing factors, giving each factor considered a score. These scores are then totalled to give a material assessment score. The example in the guidance considers four factors to determine the risk from any ACM present that has the ability to release fibres if disturbed: product type, surface treatment, the type of asbestos and the extent of any damage. Each factor is scored to give a total of between 2 and 12, as follows:

- materials with a score of ten or more should be regarded as high risk with a significant potential to release fibres if disturbed;

- materials with a score of between seven and nine should be regarded as medium risk;

- materials with a score of between five and six should be regarded as low risk; and

— materials with a score of four or below should be regarded as very low risk.

The material assessment identifies the risk from those materials that are most likely to release airborne fibres if disturbed. It does not take into account the items to be considered in the priority assessment by the duty holder to complete the risk assessment. An example of a material assessment algorithm used to arrive at a total score is set out in Table 1.

\section{Priority assessment}

The material assessment will have identified what types of ACMs are present, their location and condition. There is a further stage to consider, before the risk assessment can be completed, and that is whether the ACMs are being disturbed or are likely to be disturbed. This is considered by carrying out a priority assessment. The priority assessment algorithm detailed in the HSE guidance is also based on four factors (with the same arrangement of numbers as in the material assessment): normal occupant activity, the likelihood of disturbance, the potential for human exposure and maintenance activity.

It should be noted that no single set of factors applies equally to all premises. Four general headings have been used and one or more factors 
Table I: Material assessment algorithm

\begin{tabular}{|c|c|c|}
\hline Sample variable & Score & Examples of scores \\
\hline $\begin{array}{l}\text { Product type (or debris from } \\
\text { product) }\end{array}$ & 2 & $\begin{array}{l}\text { Asbestos-reinforced composites (plastics, resins, mastics, } \\
\text { roofing felts, vinyl floor tiles, semi-rigid paints or } \\
\text { decorative finishes, asbestos cement, etc) } \\
\text { Asbestos insulating board, mill boards, other low-density } \\
\text { insulation boards, asbestos textiles, gaskets, ropes } \\
\text { and woven textiles, asbestos paper and felt } \\
\text { Thermal insulation (eg pipe and boiler lagging), sprayed } \\
\text { asbestos, loose asbestos, asbestos mattresses and } \\
\text { packing }\end{array}$ \\
\hline Extent of damage/deterioration & $\begin{array}{l}0 \\
1 \\
2\end{array}$ & $\begin{array}{l}\text { Good condition: No visible damage } \\
\text { Low damage: A few scratches or surface marks, broken } \\
\text { edges on boards, tiles, etc } \\
\text { Medium damage: Significant breakage of materials or } \\
\text { several small areas where material has been damaged } \\
\text { revealing loose asbestos fibres } \\
\text { High damage or delamination of materials, sprays and } \\
\text { thermal insulation: Visible asbestos debris }\end{array}$ \\
\hline Surface treatment & $\begin{array}{l}0 \\
1\end{array}$ & $\begin{array}{l}\text { Composite materials containing asbestos, reinforced } \\
\text { plastics, resins, vinyl tiles } \\
\text { Enclosed sprays and lagging, asbestos insulating board } \\
\text { (with exposed face painted or encapsulated), asbestos } \\
\text { cement sheets, etc } \\
\text { Unsealed asbestos insulating board, or encapsulated lagging } \\
\text { and sprays } \\
\text { Unsealed laggings and sprays }\end{array}$ \\
\hline Asbestos type & $\begin{array}{l}1 \\
2 \\
3\end{array}$ & $\begin{array}{l}\text { Chrysotile } \\
\text { Amphibole asbestos excluding crocidolite } \\
\text { Crocidolite }\end{array}$ \\
\hline Total score & & \\
\hline
\end{tabular}

can be taken into account and averaged under each heading to suit the circumstances. The priority assessment algorithm is detailed in Table 2.

\section{The overall risk assessment}

It is anticipated that the surveyor will provide the material assessment and the duty holder will provide the priority assessment. The scores from the material assessment are added to the scores of the priority assessment to determine the overall risk assessment. If there are parts of the premises which cannot be inspected (such as roofs and heating ducts and behind ceiling tiles and wall partitions), ACMs should be presumed to be present, unless there is strong evidence to the contrary.

\section{The management plan}

The carrying out of risk assessments alone does not amount to compliance with Regulation 4 of CAWR. The risk assessments simply enable a duty holder to assess the options and determine the course of action required.

\section{Written management plan}

If the risk assessment demonstrates that asbestos is or is likely to be present in any part of the premises, the duty holder must ensure that the extent of the risk is determined and prepare a written management plan which:

- identifies those parts of the premises concerned; and

- specifies the measures which are to be taken for managing the risk.

If ACMs are in good condition and unlikely to be disturbed or damaged it may be safer to leave them in place, label them clearly with a warning 
Table 2: Priority assessment algorithm

\begin{tabular}{|c|c|c|}
\hline Assessment factor & Score & Examples of score variables \\
\hline \multicolumn{3}{|l|}{ Normal occupant activity } \\
\hline Main type of activity in area & $\begin{array}{l}0 \\
1 \\
2 \\
3\end{array}$ & $\begin{array}{l}\text { Rare disturbance activity (eg little-used store room) } \\
\text { Low disturbance activities (eg office-type activity) } \\
\text { Periodic disturbance (eg industrial or vehicular } \\
\text { activity which may contact ACMs) } \\
\text { High levels of disturbance (eg fire door with } \\
\text { asbestos insulating board sheet in constant use) }\end{array}$ \\
\hline Secondary activities for area & As above & As above \\
\hline $\begin{array}{l}\text { Likelihood of disturbance } \\
\text { Location }\end{array}$ & $\begin{array}{l}0 \\
1 \\
2 \\
3\end{array}$ & $\begin{array}{l}\text { Outdoors } \\
\text { Large rooms or well-ventilated areas } \\
\text { Rooms up to } 100 \mathrm{~m}^{2} \\
\text { Confined spaces }\end{array}$ \\
\hline Accessibility & $\begin{array}{l}0 \\
1 \\
2 \\
3\end{array}$ & $\begin{array}{l}\text { Usually inaccessible or unlikely to be disturbed } \\
\text { Occasionally likely to be disturbed } \\
\text { Easily disturbed } \\
\text { Routinely disturbed }\end{array}$ \\
\hline Extent/amount & $\begin{array}{l}0 \\
1 \\
2 \\
3\end{array}$ & $\begin{array}{l}\text { Small amounts or items (eg strings, gaskets) } \\
\leq 10 \mathrm{~m}^{2} \text { or } \leq 10 \mathrm{~m} \text { pipe run } \\
>10 \mathrm{~m}^{2} \text { to } \leq 50 \mathrm{~m}^{2} \text { or }>10 \mathrm{~m} \text { to } \leq 50 \mathrm{~m} \text { pipe run } \\
>50 \mathrm{~m}^{2} \text { or }>50 \mathrm{~m} \text { pipe run }\end{array}$ \\
\hline \multicolumn{3}{|l|}{ Human exposure potential } \\
\hline Number of occupants & $\begin{array}{l}0 \\
1 \\
2 \\
3\end{array}$ & $\begin{array}{l}\text { None } \\
1 \text { to } 3 \\
4 \text { to } 10 \\
>10\end{array}$ \\
\hline Frequency of use of area & $\begin{array}{l}0 \\
1 \\
2 \\
3\end{array}$ & $\begin{array}{l}\text { Infrequent } \\
\text { Monthly } \\
\text { Weekly } \\
\text { Daily }\end{array}$ \\
\hline Average time area is in use & $\begin{array}{l}0 \\
1 \\
2 \\
3\end{array}$ & $\begin{array}{l}<I \text { hour } \\
>I \text { to }<3 \text { hours } \\
>3 \text { to }<6 \text { hours } \\
>6 \text { hours }\end{array}$ \\
\hline \multicolumn{3}{|l|}{ Maintenance activity } \\
\hline \multirow[t]{3}{*}{ Type of maintenance activity } & $\begin{array}{l}0 \\
1\end{array}$ & $\begin{array}{l}\text { Minor disturbance (eg possibility of contact when } \\
\text { gaining access) } \\
\text { Low disturbance (eg changing light bulbs in asbestos }\end{array}$ \\
\hline & 2 & $\begin{array}{l}\text { insulting board ceiling) } \\
\text { Medium disturbance (eg lifting one or two asbestos } \\
\text { insulation board ceiling tiles to access a valve) }\end{array}$ \\
\hline & 3 & $\begin{array}{l}\text { High levels of disturbance (eg removing a number of } \\
\text { asbestos insulating board ceiling tiles to replace } \\
\text { a valve or for recabling) }\end{array}$ \\
\hline Frequency of maintenance activity & $\begin{array}{l}0 \\
1 \\
2 \\
3\end{array}$ & $\begin{array}{l}\text { ACM unlikely to be disturbed for maintenance } \\
\leq \text { I per year } \\
>\text { I per year } \\
>\text { I per month }\end{array}$ \\
\hline
\end{tabular}

Implementation of management plan sign and monitor their condition. A work permit system also should be introduced to ensure relevant information is provided before any work is carried out. Alternatively, if the ACM is in poor condition or likely to be disturbed or damaged then it may require repairing, sealing, enclosing or removing; this should be carried out by a competent contractor.

Once the plan has been prepared, the duty holder must ensure that the measures specified in the plan are implemented and recorded and that information about the location and condition of the ACMs is provided 
to every person likely to disturb them. This will include anyone whose work involves dealing with the fabric of the building such as plumbers, joiners, electricians or computer and cabling engineers. It also extends to the emergency services. To do this effectively duty holders should:

- keep and maintain a readily available up-to-date record of the location, condition, maintenance and removal of all ACMs on the premises;

- repair, seal or remove ACMs where there is a risk of exposure due to their condition or location;

— maintain ACMs in a good state of repair, regularly monitoring their condition; and

- have procedures in place to ensure that, where work may disturb ACMs, it is done in accordance with the other requirements of CAWR.

The plan should be reviewed at regular intervals to ensure the measures specified are implemented and recorded or when any significant changes are envisaged, such as refurbishment works.

Leasehold arrangements

\section{Leasehold property specifics}

\section{Multi-let premises}

In multi-let premises, responsibility for the maintenance of the common parts, services, external fabric and main structure of the building will invariably fall on the landlord. As the duty holder, the landlord will be expected to arrange for asbestos surveys to be carried out and for copies of asbestos registers to be produced for each tenant.

\section{Repairing obligations}

Where a lease places repairing obligations on a tenant, the landlord should ensure that the tenant is aware of his obligations under Regulation 4 and satisfy himself that the tenant complies with those obligations. Where the landlord himself owes the repairing obligation it is likely that he will need to gain access to the premises to carry out the necessary surveys. The lease will dictate the terms of entry and whether survey costs are recoverable under the service charge.

\section{TAX RELIEF}

Businesses will draw some consolation from the fact that the cost of removal or treatment of asbestos in buildings may qualify for contaminated land tax relief. Under the Finance Act $2001,{ }^{12}$ tax relief of up to 150 per cent may be available for companies which incur expenditure on land remediation including the removal of asbestos from buildings. Given the current corporation tax of 30 per cent, this represents a recovery of 45 per cent of the costs in cash terms.

The disposal of asbestos may be another consideration for affected property owners and landfill tax may apply. It may be possible to get 


\section{Civil and criminal penalties for failure}

advance agreement from HM Customs and Excise that waste from contaminated land can be exempted from the landfill tax.

Where the increased costs of decontamination are so high that property owners are tempted to sell their property, it is likely it will be for a reduced price to take into account the cost of decontamination. It may be possible for the vendor to negotiate with the purchaser regarding the tax relief the purchaser will benefit from.

\section{CONSEQUENCES OF FAILING TO MANAGE ASBESTOS RISK}

Criminal penalties for breaching asbestos regulations can be severe. Offenders could find themselves facing unlimited fines or prison sentences. In R. $v$ Brintons [1999], ${ }^{13}$ a fine of $£ 100,000$ plus costs was imposed on an employer for failing to prevent the exposure of employees to asbestos. This was despite the employer demonstrating an exemplary health and safety record and taking prompt action to deal with the breach. Custodial sentences also can be given in severe cases. The first was imposed by Bristol Crown Court in 1996 on a defendant who demolished asbestos-containing sections of a factory with an excavator. $^{14}$

Fines for breaching the general duties under the HSWA can be up to $£ 20,000$ per offence in the magistrate's court. Unlimited fines can be imposed in the crown court. Prosecutions following breaches of the asbestos regulations would be likely to be based on breaches of the general duties under the HSWA as well as on breaches of CAWR for which the maximum fine per offence is $£ 5,000$ in the magistrates court and unlimited in the crown court. The HSE intends to enforce asbestos regulations rigorously and it is likely that charges will be brought in such a way that cumulative fines can be imposed to penalise offenders heavily.

In addition, regard should be given to the risk of civil liabilities. Britain is becoming a more litigious society. The advent of 'no win, no fee' litigation and the increasing public awareness of the link between asbestos exposure and the incidence of disease has led to an increase in claims for compensation. In a recent case, ${ }^{15}$ the family of a doctor was awarded compensation of $£ 1.15 \mathrm{~m}$, following his death from mesothelioma which was alleged to have been caused by exposure to asbestos during his employment at Middlesex Hospital. The doctor used an extensive system of underground passages to walk from one building to another, several times a day. The passages were found to contain pipes and cables, many of which were lagged with asbestos and in a state of disrepair having been damaged by passing trolleys.

It also seems inevitable that insurance companies will want some proof of compliance when renewing employer's liability insurance. Failure to comply is likely to increase the possibility of future claims from employees, contractors or other users of premises who may contract asbestos-related diseases and may result in companies finding themselves uninsured against those claims. 


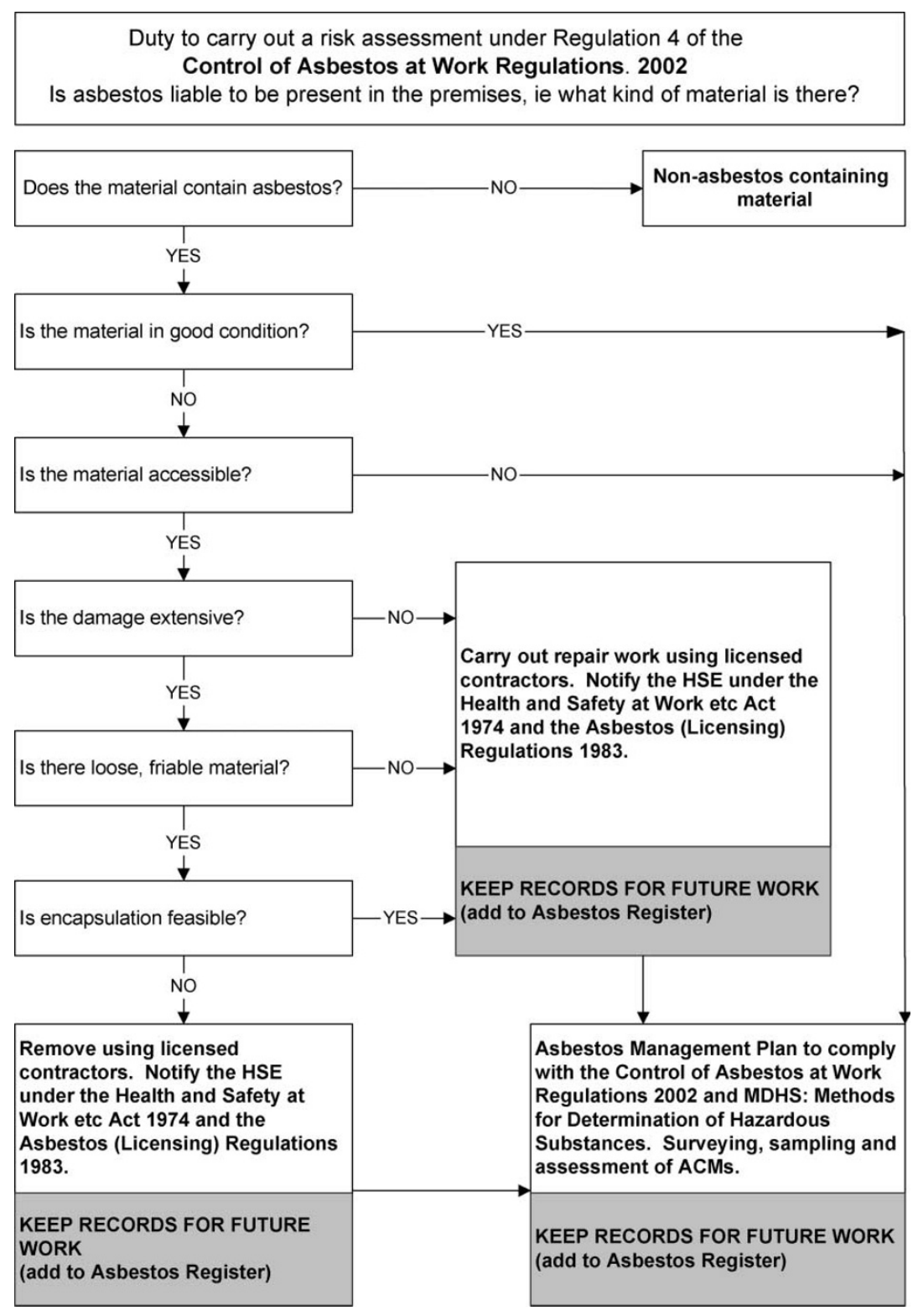

Figure 1: A guide to asbestos management

\section{SUMMARY}

Asbestos is the biggest occupational health risk ever faced by workers in Britain. The Control of Asbestos at Work Regulations have been introduced to ensure duty holders ascertain whether their properties contain asbestos and properly manage the risk posed to building and maintenance workers in order to prevent or, at the very least, reduce the debilitating and often fatal effects caused by exposure to asbestos fibres. If anyone owns, manages or has responsibilities for non-domestic premises or common areas of domestic premises then they are likely to be a duty holder. Duty holders must ensure information on the location and condition of asbestos is available to anyone liable to work with it or 
disturb it, or where it is in poor condition arrange for its enclosure or removal. Figure 1 provides guidance as to the process required in managing asbestos risks likely to be followed by any such duty holder.

\section{References}

Health and Safety Executive (2003) Surveying, Sampling and Assessment of Asbestos-containing Materials, HSE.

\section{Notes}

1. SI $2002 / 2675$

2. SI $2002 / 2675$

3. SI $1987 / 2115$

4. SI $1992 / 3067$

5. SI $1983 / 1649$

6. SI 1974 c. 37

7. SI $1999 / 3242$

8. SI $1999 / 347$

9. SI $1994 / 3140$

10. 1972 c. 35

11.

12. 2001 c. 9

13. R v Brintons

14. (1996)

15. Plaintiff $\mathrm{F}-\mathrm{v}-$ British Gas http://www.legislation.hmso.gov.uk/si/si2002/200022675.htm\#4

http://www.legislation.hmso.gov.uk/si/si2002/20002675.htm

http://www.legislation.hmso.gov.uk/si/si1987/Uksi_19872115_en_1.htm

http://www.legislation.hmso.gov.uk/si/si1992/Uksi_19923067_en_1.htm

http://www.butterworths.co.uk/legislation/index.htm

http://www.butterworths.co.uk/legislation/index.htm

http://www.legislation.hmso.gov.uk/si/si1999/19993242.htm

http://www.legislation.hmso.gov.uk/si/si1999/19990437.htm

http://www.legislation.hmso.gov.uk/si/si1994/Uksi_19943140_en_1.htm

http://www.butterworths.co.uk/legislation/index.htm

http://www.hse.gov.uk/pubns/mdhs/pdfs/mdhs100.pdf

http://www.legislation.hmso.gov.uk/acts/acts2001/20010009.htm

CA (Crim Div) LTL 22/6/99

Bristol Crown Court

http://www.lkaz.demon.co.uk/ban38.htm 